\title{
Convergência e divergência na conexão entre gênero e letramento: novos avanços*
}

Nelly P. Stromquist

University of Southern California

Correspondência:

Nelly P. Stromquist

Rossier School of Education

University of Southern California

Los Angeles, CA 90089-0031

* Traduzido do original Convergence and divergence in the gender and literacy connection: recent developments, por Denise Trento Rebello de Souza.
Resumo

Este artigo examina as hipóteses teóricas e os resultados empíricos de três perspectivas distintas que orientam a pesquisa em alfabetização de adultos. É baseado em uma revisão da literatura recente sobre o tema, cuja maior parte apareceu em livros e periódicos em língua inglesa. As perspectivas são: alfabetização como uma habilidade básica descontextualizada; alfabetização como prática social imersa em condições locais (letramento); e alfabetização (letramento) como ferramenta para o empowerment individual e coletivo, especialmente de mulheres.

As divergências en contradas referem- se: ao conceito de alfabetização/letramento, ao potencial atribuído à alfabetização para 0 desenvolvimento nacional e melhoria das condições sociais, à possibilidade de uma medida padronizada válida das habilidades de alfabetização, ao papel dos mediadores no processo de alfabetização e ao poder do contexto na determinação do letramento como uma prática estável. As convergências existem ao se considerar os programas de alfabetização como de difícil implementação e carentes de comprometimento político a longo prazo, de capacitação adequada de professores e de recursos financeiros apropriados aos objetivos declarados de alfabetização. Da perspectiva do empowerment de mulheres, o conteúdo das mensagens letradas e a necessidade de suporte multissetorial são cruciais. Taxas de analfabetismo estão decaindo lentamente em todo o mundo, mas o número absoluto daqueles incapazes de ler ou escrever está aumentando. Mulheres continuam a representar dois terços dos analfabetos. Condições atuais de pobreza e os mecanismos implantados para conter suas manifestações trabalham contra a participação dos alunos de programas de alfabetização e contra a subsequente aplicação das habilidades de alfabetização à vida cotidiana.

Palavras-chave

J ovens e adultos - Alfabetização - Mulheres. 


\section{Convergence and divergence in the gender and literac y c onnection: recent developments}

Nelly P. Stromquist

University of Southern California

\section{Abstract}

This article examines the theoretical assumptions and empirical findings of three discrete perspectives guiding research on adult literacy. These perspectives are: literacy as a decontextualized basic skill, literacy as a social practice embedded in local conditions, and literacy as a tool for individual and collective empowerment, especially for the empowerment of women. Divergence exists along several lines: the conception of literacy, the imputed potential of literacy to contribute to national development and modifying social conditions, the potential for a valid standardized measurement of literacy skills, the role of mediators in the processing of print literacy, and to the power of context to determine the possibility of literacy to becoming a stable practice. Convergence exists when considering literacy programs difficult to implement and in great need of long-term political commitment, adequate teacher training, and financial resources appropriate for the expressed literacy objectives. From the perspective of women's empowerment, the content of literacy messages and participatory learning methodologies in literacy programs, as well as the need for multisectoral support, is crucial. Iliteracy rates are slowly decreasing throughout the world, but the absolute number of those unable to read or write is increasing. Persistently, women comprise two-thirds of the illiterates. Current poverty conditions and the mechanisms in place to counter their manifestations work against the participation of learners in literacy programs and their subsequent application of literacy skills to everyday life. The article is based on a review of the recent literature on adult literacy, most of which has appeared in books and journals in English.

Keywords

Youngsters and adult - Literacy - Women.
Nelly P. Stromquist

Rossier School of Education University of Southern California Los Angeles, CA 90089-0031 
Nosso mundo contemporâneo, submetendo-se às fortes e visíveis influências da economia, tecnologia e cultura globalizadas, requer níveis de educação cada vez mais altos para que uma pessoa tenha acesso a salários decentes e ascensão social. Atualmente, em um mundo que depende do letramento, grande número de pessoas permanece à margem das promessas de modernidade e progresso, muitas delas aprisionadas em baixos níveis de educação e com habilidades de leitura e escrita muito limitadas. Dentro desse contexto de polarização educacional, várias organizações humanitárias e alguns governos têm-se preocupado com o fato de que o número absoluto de "analfabetos" continua crescendo, prenunciando, assim, a exclusão contínua e existência marginal dessas pessoas.

Os conceitos de alfabetização e letramento, sua medida, e a avaliação de seu potencial para criar uma sociedade mais igualitária ou avançada têm sofrido mudanças graduais durante os últimos vinte anos. Três perspectivas diferentes coexistem em vários graus de comunicação entre si. Elas se originam de atores sociais distintos, cada um dos quais concebe a alfabetização (ou o letramento) desempenhando papéis diferentes no processo de transformação social. 0 primeiro grupo, formado majoritariamente por governos e agências internacionais, considera que a alfabetização of erece um caminho crucial para o desenvolvimento nacional ao produzir mão-de-obra mais preparada e cidadãos mais informados em muitas dimensões da vida coletiva, desde criar crianças mais saudáveis até gerar maior participação política em eleições. 0 segundo grupo é formado por acadêmicos, principalmente nas áreas de lingüística e antropologia. Este grupo considera que o letramento é, mais que um conjunto de habilidades abstratas, uma prática social e assim argumenta não haver um único letramento, mas múltiplos letramentos. 0 terceiro grupo, que inclui educadores populares e feministas, vê o letra- mento como uma ferramenta de que indivíduos precisam para se capacitar e se tornarem agentes na sua própria luta por justiça social e cidadania plena.

Este artigo, por conseguinte, não apresenta uma tese única, mas, ao invés disso, é o resultado de várias avaliações e contribuições de diversas disciplinas. As três perspectivas introduzidas acima produziram diferentes definições e medidas de alfabetização/letramento. Do mesmo modo, elas produzem diferentes avaliações do impacto do letramento, defendem formas distintas de treinamento de alfabetizadores, fazem afirmações contrastantes sobre o uso e potencial do letramento, e, finalmente, sustentam diferentes visões sobre a importância da autonomia individual. É meu propósito discutir essas três perspectivas detalhadamente, realçando suas conseqüências para as políticas públicas. Exploro também a possibilidade de produzir uma síntese de suas melhores características compatíveis.

Alfabetização como uma
habilidade básic a para o
desenvolvimento

A visão dominante de alfabetização é a de que ela é uma habilidade que permeia contextos e experiências particulares. Também considera que a alfabetização representa a base sobre a qual se constrói uma nação economicamente mais produtiva e permite que seus cidadãos operem no que se tornará inevitavelmente um ambiente complexo. Uma vasta literatura baseada em pesquisas mostra que as pessoas alfabetizadas atribuem maior valor à nutrição, saúde, e educação de suas crianças, de modo que benefícios intergerações provêm da alfabetização (Windham, 1999). Há evidências de que a alfabetização pode contribuir para um aumento da auto-estima e da confiança neles por parte dos outros, e para a assertividade 
na interação social, permitindo assim que os indivíduos aumentem a percepção de si mesmos como agentes diante da família e da comunidade. Porém, é importante observar que a maioria dos estudos sobre o poder da alfabetização confunde o impacto da alfabetização com o da escolarização, particularmente com o número de anos de estudo.

No discurso oficial, cabe à alfabetização prover conhecimento orientado para a informação. Afirma-se que a alfabetização promove conhecimento que pode ser categorizado e orientado para o futuro, capacitando aqueles que podem ler e escrever a ganhar acesso ao mundo público e facilitando a resolução de contradições por meio de análise e reflexão. Considerada como um meio de acesso ao conhecimento moderno, a alfabetização é contrastada freqüentemente com o conhecimento tradicional, o qual considera-se ter uma ênfase em unidade, inteireza e interconexão, bem como em aprender com o passado (Teasdale, 1997).

Vinculada a essas grandes promessas da alfabetização, continua existindo uma relativa falta de entendimento por parte dos idealizadores de políticas educacionais com relação ao seu potencial, suas limitações e exigências para implementação. Não é incomum encontrar representantes de governos que fixam objetivos quanto ao analfabetismo tais como sua "redução em $80 \%$ em um período de um ano", não levando em consideração resultados de pesquisas existentes para determinar se tais metas são factíveis no contexto particular nos quais elas serão aplicadas. Por exemplo, economistas do Banco Mundial ainda produzem documentos em que há referências à necessidade de "erradicar a peste do analfabetismo" (Ritzen, 2000), como se 0 analfabetismo fosse algo contraído de um vírus que flutua no ar.

Concomitante com a compreensão oficial simplista de analfabetismo, tem havido uma visão dicotômica da sua definição, a qual estabelece um limite claro entre alfabetizados e analfabetos. Essa visão continua operando por meio do uso de medidas baratas de alfabetização baseadas na auto-avaliação ou na utilização do desempenho educacional como um substituto para habilidades letradas (Murray, 1999), ambos derivados de dados de recenseamentos nacionais e pesquisas em domicílios. A Unesco mudou sua concepção de alfabetização, que, nos anos 1950, era definida como a capacidade de o indivíduo "entender e ler uma sentença simples e curta sobre sua vida cotidiana", para uma abordagem mais complexa e relacional nos anos 1970, definindo então como alfabetizada

uma pessoa que pode desempenhar todas as atividades nas quais a alfabetização é requerida para o funcionamento ef etivo de seu grupo e comunidade e também para habilitá-la a continuar usando a leitura, escrita, e cálculo para seu próprio desenvolvimento e o da comunidade. (apud Murray, 1999)

A partir dos anos 1960, houve avanços significativos nos instrumentos de medida da alfabetização, baseados em desenvolvimentos da psicometria para seleção de itens e ordenação deles de acordo com seu nível de dificuldade. Definindo alfabetização como "um modo de comportamento adulto" (Murray, 1999, p. 220), medidas mais refinadas distinguiram três modalidades (prosa, documento, e alfabetização quantitativa) ${ }^{1}$ e avaliaram a alfabetização em uma escala contínua de 0 a 500 pontos, classificando indivíduos em cinco

1. Os três domínios de alfabetização são medidos da seguinte forma: 1) prosa: conhecimento e habilidades para entender e utilizar informação de textos, incluindo editoriais, notícias e ficção; 2) alfabetização de documentos: conhecimento e habilidades necessárias para localizar e utilizar informação contida em vários formatos, incluindo formulários de solicitação de emprego, tabelas de horários de meios de transporte, tabelas e gráficos; 3) alfabetização quantitativa: conhecimento e habilidades necessárias para a aplicação de operações aritméticas a números contidos em materiais impressos, tais como calcular o saldo bancário, preencher um pedido de compra ou determinar a quantidade de juros em um empréstimo (Hamilton and Barton, 1998, p. 369). 
níveis de proficiência de alfabetização. ${ }^{2}$ Essa abordagem, conhecida como a Pesquisa Nacional de Alfabetização de Adultos (National Adult Literacy Survey - NALS), foi aplicada primeiro nos EUA, em 1994, e novamente em 1996 e 1998 com pessoas de 16 anos ou mais. Tal avaliação da alfabetização é baseada principalmente em perguntas abertas e requer cerca de uma hora para sua aplicação em uma entrevista individual. Por causa de seu custo, foi só usada em países industrializados. A NALS constatou que entre americanos com dez anos de escolaridade, quase $25 \%$ obtiveram apenas resultados equivalentes às habilidades de alfabetização de 4a série ou abaixo (Wagner e Venezky, 1999), o que indica que anos de escolaridade representam um substituto impreciso para competências de alfabetização reais. A pesquisa também constatou que adultos com baixas habilidades de alfabetização normalmente não relatam que essa deficiência Ihes causa qualquer dificuldade séria. Como Murray relata, "Quando perguntados se suas habilidades de leitura eram suficientes para satisfazer suas necessidades cotidianas, a maioria esmagadora dos respondentes afirmou que sim, independentemente de seu nível de habilidade testada" (1999, p. 221). Isso é reflexo provavelmente do fato de que muitos indivíduos têm empregos que não requerem o uso de alfabetização ou que eles aprenderam a lidar com suas habilidades, mesmo que insuficientes, ou ambas as coisas.

Um problema intrigante, muito relacionado ao potencial da alfabetização para meIhorar as oportunidades de vida da pessoa, enfoca a capacidade da alfabetização contribuir para aperfeiçoar o raciocínio e o pensamento conceitual. Tal hipótese foi explorada vários anos atrás em um estudo que comparou pessoas que foram alfabetizadas na escola com outras que foram alfabetizadas em sua língua materna por meios informais (Scribner e Cole, 1981). 0 estudo, que enfocou o povo Vai, na Libéria, África, constatou que melhorias cognitivas surgiram em pessoas que tinham sido alfa- betizadas em escolas, mas não naquelas alfabetizadas por meios informais. Um estudo de Bernardo, em 1998, testando a mesma premissa, mas enfocando agora sujeitos das Filipinas, empregou uma estrutura de pesquisa quase experimental, que compara habilidades cognitivas de três grupos (analfabetos, alfabetizados por meio de educação formal, e alfabetizados por meio de educação não-formal e informal). Bernardo examinou cinco habilidades cognitivas (compreensão conceitual, organização conceitual, comparação conceitual, raciocínio dedutivo, e explicação ou raciocínio indutivo). Ele não encontrou "nenhuma transformação generalizada no modo de pensar em direção a um processamento mais formal ou abstrato da informação" (1998, p. 56), mas ele descobriu que, em relação às pessoas dos outros dois grupos, aquelas que foram alfabetizadas na escola eram capazes de dar explicações mais completas e de produzir menos respostas que não abordavam o que estava sendo perguntado. Ele atribuiu essa mudança à socialização recebida nas escolas em relação a respostas explícitas, focadas e completas e não à alfabetização em si mesma. ${ }^{3}$ Ele também verificou que melhorias na capacidade para categorizar estavam ligadas ao grau de integração da alfabetização em práticas cotidianas. Comunidades letradas - isto é, aquelas com atividades como discussões de grupo, redação de boletins informativos e oferecimento de seminários e workshops - promovem mudanças cognitivas. Bernardo constatou que até

2. Cada nível de proficiência inclui sua própria faixa de pontuação. 0 nível mais baixo tem pontuações de 0 a 225, 0 segundo de 226 a 275, 0 terceiro de 276 a 325, o quarto de 326 a 375 e o quinto e último entre 376 e 500 . Observa-se que enquanto a faixa para os níveis de 2 a 4 é de cerca de 50 pontos, a faixa para o nível mais baixo compreende 225 pontos e a dos níveis mais altos 120 pontos, coisa que é realmente bastante arbitrária (para mais detalhes, veja Barton, 1999 e Hautecourt, 2000).

3. Este resultado oferece alguma explicação para a constante referência de mulheres analfabetas no Brasil: a sua esperança de que a alfabetização pudesse ajudá-las a falar melhor (Stromquist, 1997). 
mesmo os membros analfabetos da comunidade participam das práticas comunitárias que empregam a alfabetização; portanto, até mesmo os membros analfabetos alteram o modo como processam informação, como resultado da integração de práticas letradas. (1998, p. 85)

Em termos positivos, Bernardo demonstrou uma vez mais que os analfabetos não são debilitados psicológica ou mentalmente, uma vez que seres humanos - independentemente de níveis educacionais - são capazes de entender conceitos e utilizá-los para desenvolver mapas cognitivos do mundo à sua volta. Em termos menos positivos, Bernardo constatou que, como muitas outras habilidades cognitivas, a alfabetização não é adquirida facilmente. Ele concluiu que a "alfabetização precisa ser apoiada sobre outras habilidades no repertório existente da pessoa" (Bernardo, 1998, p. 133). Ferreiro sustenta uma visão semelhante de alfabetização quando critica a ênfase das escolas públicas latino-americanas na decodificação à custa do significado, sem apresentar um modelo das funções sociais do letramento (apud Dexter, 1998). A tendência de a alfabetização ser enraizada em práticas cotidianas nos leva a concluir que índices de alfabetização podem não ser indicadores precisos de até que ponto práticas de letramento foram estabelecidas nas comunidades; na realidade, tais índices podem tender a superestimar os possíveis usos do letramento.

Apesar de Bernardo não ter constatado nenhum efeito da alfabetização sobre qualquer habilidade cognitiva específica, deve ser observado que os adultos em seu estudo tinham no máximo atingido 0 50 ano de escola primária, assim seus resultados não constituem um teste da capacidade da educação para alterar a formação de conceitos. A alfabetização é proposta por muitos não como o nível mínimo e final de habilidades básicas de leitura e escrita, mas, ao contrário, como um meio para atingir níveis de educação e conhecimento cada vez mais altos.
É pertinente também notar que as práticas comunitárias que integravam habilidades de alfabetização nas comunidades Filipinas eram aquelas localizadas em organizações populares ou comunitárias (p. 104); o estudo de Bernardo, por conseguinte, reconhece como importante não somente o contexto, mas também um contexto nutrido por laços organizacionais.

Posições que defendem o acesso à alfabetização no contexto do desenvolvimento nacional são defendidas porque possibilitam que os indivíduos processem informações que transcendam um tempo e circunstância particulares; ou seja, que os indivíduos lidem com descrições de objetos ou eventos com os quais eles podem não ter nenhum contato direto. Dexter et al. (1998) introduziram o conceito de "linguagem descontextualizada," definido como

linguagem independente do orador/autor, bem como do ouvinte/leitor, e [na qual] o significado deve ser derivado principalmente das próprias palavras e não do contexto, para que tenham aproximadamente 0 mesmo significado para diferentes pessoas. (p. 142)

Dexter et al. afirmam ainda que para ser compreensível a uma ampla audiência, a linguagem descontextualizada exibe características textuais que a distinguem da linguagem conversacional. Uma característica importante é o tipo de vocabulário requerido para tornar o significado tão explícito quanto possível. Enquanto a linguagem conversacional usa freqüentemente um vocabulário vago ou geral que é clarificado através do contexto ou do conhecimento compartilhado, o vocabulário da linguagem descontextualizada deve ser o mais específico possível para restringir a interpretação; as palavras devem ter significado padronizado. Uma segunda característica relaciona-se à gramática. Sentenças conversa- 
cionais são tipicamente simples e fragmentadas por várias razões: os oradores têm pouco tempo para compor orações complexas, há menos necessidade da clareza que a gramática complexa cria, e a entonação e as pausas transmitem parte da informação que as estruturas gramaticais complexas comunicam. Uma terceira característica refere-se à estrutura de discurso da linguagem descontextualizada, a qual é mais monológica do que dialógica. Expressões mais longas do que é usual em conversação aumentam a carga cognitiva para orador e ouvinte; e devem ser especificadas relações lógicas entre idéias com palavras e expressões como "porque", "em contraste", "em lugar de", "por isso", ou "então", enquanto relações temporais são descritas com expressões como "depois disso", "então, enquanto isso", ou "pela manhã". Ainda uma quarta característica é a impessoalidade do orador/ouvinte no texto. 0 orador/ouvinte apresenta-se como um transmissor objetivo de verdades ao invés de um indivíduo com uma perspectiva particular (p. 144-145).

Dexter et al. (1998) consideram que escolas, sendo ambientes saturados de conversação, são cenários básicos para a aquisição de linguagem descontextualizada. ${ }^{4}$ Esses pesquisadores, em um estudo sobre o impacto da instrução materna na zona rural do México, constataram que a capacidade para processar linguagem descontextualizada é altamente correlacionada com atividades de escuta, leitura e fala ligadas à saúde. Descobriram também que o número de anos de escolaridade era um indicador significativo da capacidade de enunciar definições descontextualizadas de substantivos, de entender mensagens faladas e escritas sobre saúde, embora em todos os níveis de escolarização houvesse grande variação nas capacidades de leitura das mulheres (Dexter et al., 1998). Eles também descobriram um dado interessante: as barreiras de alfabetização criam barreiras de linguagem oral, na medida em que mulheres com pouco ou nenhum domínio da alfabetização tiveram dificuldades em seguir instruções e mensagens transmitidas oralmente por médicos e enfermeiras.

Pesquisas recentes realizadas por economistas estão contribuindo para a compreensão da alfabetização por meio da identificação do "analfabeto próximo", definido como uma pessoa que não sabe ler, mas vive com alguém que sabe. A suposição de que os alfabetizados realizam tarefas de leitura e escrita para analfabetos foi testada empiricamente observando o efeito de fatores internos ao domicílio (ou seja, os efeitos da presença de membros alfabetizados na casa) sobre a altura de crianças em Papua-Nova Guiné (Gibson, 2001). Esse estudo constatou que havia efeitos positivos decorrentes do fato de haver uma pessoa alfabetizada na casa, embora o acesso direto à alfabetização (ou seja, a própria pessoa ser alfabetizada) tivesse um maior efeito positivo. Gibson argumenta que o grupo mais carente de uma intervenção projetada para melhorar a alfabetização é aquele no qual todas as pessoas que moram na casas são analfabetas. Ele também propõe que, em vez de apenas calcular o índice de alfabetização de adultos em uma determinada comunidade, os planejadores deveriam verificar como são distribuídos os adultos entre os domicílios.

É fato bem conhecido que, enquanto os governos têm uma expectativa de que um grande número de matrículas em programas de alfabetização seja efetuado, o padrão habitual é ocorrer um menor número de matrículas do que o previsto; além disso, muitos abandonam o programa logo após se matricularem. Em seu estudo sobre São Paulo, Stromquist (1997) descobriu que as razões

4. Citando uma pesquisa de Snow, Dexter et al. (1998) afirmam a visão de que muitos problemas de leitura ou escrita que crianças enfrentam após adquirir um nível simples de habilidades são de fato problemas de processamento e produção de linguagem descontextualizada, tanto escrita quanto oral. 
declaradas pelos alunos de cursos de alfabetização para participarem de programas de alfabetização são muito diferentes daquelas manifestadas pelos idealizadores dos programas. Embora os programas de alfabetização possam ser vistos oficialmente como uma das principais formas de trazer idéias modernas para as comunidades ou torná-las mais produtivas economicamente, as razões pessoais dos indivíduos que deles participam podem ser mais modestas: desde, por exemplo, aprender a assinar seu nome até a de adquirir um vocabulário mais amplo, ou somente como uma desculpa para deixar a casa e desfrutar de algumas horas de relaxamento. Em terceiro lugar, também ocorre que programas que pretendem atender "analfabetos" na realidade atraem indivíduos com vários graus de proficiência em leitura e escrita. Stromquist (1997) constatou que as capacidades para decodificar e compreender textos variavam consideravelmente entre as mulheres que participavam do programa, desde aquelas que nunca haviam estado na escola até outras que tinham alcançado $05^{\circ}$ ano na escola primária.

\section{Alfabetização vista como enraizada em prátic as cultura is (letramento)}

Nas duas últimas décadas, vários acadêmicos, particularmente nos campos da lingüística e da antropologia (e em menor grau no campo da semiótica, da psicologia e da história), têm desafiado a idéia de que existe uma divisão clara entre pessoas alfabetizadas e analfabetas e de que as habilidades letradas podem ser adquiridas independente do contexto social no qual as pessoas vivem. Conhecida como New Literacy Studies (NLS), essa escola de pensamento e pesquisa tem examinado as experiências cotidianas das pessoas, procurando exemplos nos quais a comunicação e o uso da palavra escrita acontecem (Heath, 1983; Street, 1984, 1993, 1995; Gee, 1996; Gee et al., 1996; Barton, 1984; Barton e Hamilton, 1998). Tal perspectiva é também conhecida como "abordagem sociocultural", que enfatiza 0 reconhecimento do letramento em sua comunidade de práticas (Druine e Wildemeersch, 2001). Até o presente momento, os estudos foram desenvolvidos principalmente nos países de língua inglesa. Mediante estudos etnográficos, que empregam entrevistas abertas e observação, os NLS descobriram que indivíduos com vários graus de incapacidade para ler e escrever desenvolvem práticas que Ihes permitem lidar com demandas sociais apesar de suas limitadas habilidades de leitura e escrita. Investigações fascinantes que utilizam esta abordagem foram conduzidas na África do Sul em uma série de estudos de comunidades, centrados em ambientes tais como cortiços e favelas, a indústria do táxi, fazendas, escolas, e em comunidades de migrantes. Seus resultados confirmam a ligação entre habilidades letradas e prática contextual e a inventividade dos indivíduos para funcionar socialmente, mesmo com suas baixas habilidades de leitura e escrita (Kell \& Prinsloo, 1997).

Os NLS argumentam que os programas de alfabetização freqüentemente estão por demais interessados nos resultados cognitivos e não são suficientemente sensíveis ao modo como o processo de alfabetização opera para seus participantes e a como eles se adaptam à cultura que os cerca. Dois conceitos importantes usados pelos NLS são "eventos de letramento" e "práticas de letramento", os quais nos permitiram ganhar uma maior compreensão dos significados e usos do letramento. 0 primeiro conceito, proposto por Heath (1982), refere-se às ocasiões concretas nas quais a língua escrita está vinculada à natureza das intervenções dos participantes, suas estratégias e seus processos interpretativos. 0 segundo conceito, proposto por Street (1993), amplia a noção de eventos do letramento incluindo modelos e eventos culturais que ajudam a dar 
forma ao modo como os comportamentos e os significados que os acompanham são relacionados ao uso da leitura e escrita.

Os NLS constatam que os indivíduos possuem uma variedade de habilidades comunicativas e que atividades, valores, e padrões de tempo e espaço, que são familiares, influenciam suas respostas a textos escritos, variando tais respostas entre sociedades e instituições. (Heath, 1999; McEwan e Malan, 1996). Argumenta-se que as práticas do letramento só adquirem significado em contextos sociais relacionados às atividades e ao intercâmbio que ocorre no interior das culturas. Consequentemente, maior competência no letramento depende de práticas mais amplas. Por exemplo, uma das práticas letradas mais comuns tende a ser a leitura da Bíblia. Entre pessoas que não foram alfabetizadas na escola ou com baixos níveis de alfabetização é comum encontrar quem diga ser capaz de ler a Bíblia; capacidade que atribuem a uma inspiração divina (McEwan e Malan, 1996; Stromquist, 1997). Pessoas não alfabetizadas também alegam serem capazes de ler hinos religiosos. Ambas as práticas podem ser tomadas como exemplos segundo os quais a palavra impressa funciona como um auxílio da memória para textos e práticas repetitivas de forma que, em lugar de "ler", os indivíduos estão refrescando sua memória por meio de reconhecimento de letras e palavras- chave em frases familiares. Um estudo dos NLS sobre a indústria do táxi na África do Sul encontrou um índice surpreendentemente alto de analfabetismo entre motoristas (55\% entre motoristas de J ohannesburgo e Soweto), embora a exigência de letramento desta ocupação seja alta (Breier et al., 1996). Os motoristas aprenderam a lidar com seu analfabetismo por meio da memorização das regras de trânsito, associando mensagens a cores e formas para decodificar sinais e figuras e buscando o apoio de outras pessoas para mediar suas necessidades, particularmente com relação ao cumprimento da lei. 0 estudo de McEwan e Malan (1996) constatou que aquilo que é aprendido no nível da comunidade representa avenidas importantes para o status e a autoridade que os adultos podem não conseguir mediante a alfabetização escolar.

Como Heath (1999) observa, tempo e identidades futuras de família e cultura, emprego e afiliações espirituais moldam a leitura e a escrita. Outros argumentos são encontrados nos trabalhos de Lankshear e O'Connor (1999). Eles afirmam que atualmente a comunicação está mudando rapidamente, de modo que os indivíduos enfrentam uma maior integração de texto, imagens e sons no sistema de comunicação (pelo uso de rádio, televisão e vídeos) e assim eles devem estar preparados para interagir por meio de múltiplos pontos. Eles também observam que mediante sua participação em turmas de alfabetização, os estudantes buscam preencher necessidades "em todo o espectro de seus papéis e identidades sociais" (Lankshear e O'Connor, 1999, p. 32).

Investigadores dos NLS afirmam que letramento não é um conceito homogêneo (Gee 1990; Street, 1987). Ao mesmo tempo que reconhecem letramentos dominantes ou escolares, eles sustentam que existem também importantes letramentos locais ou baseados na comunidade, que são desenvolvidas por meio de práticas sociais em situações naturais. Nesta linha, tem sido afirmado até mesmo que "não existe algo como um nível de letramento" (Rogers, 2001, p. 25). Na visão desses estudiosos, referências à necessidade de alfabetização involuntariamente marginalizam os analfabetos em suas comunidades e negam as muitas habilidades comunicativas que eles conseguiram adquirir (Street, 1993; McEwan e Malan, 1996; Kell e Prinsloo, c. 1997). Investigadores dos NLS opõem-se às tentativas de medir a alfabetização por meio de instrumentos de larga escala e de fazer comparações internacionais, por considerarem que tais instrumentos descontextualizam o conhecimento das comunidades e oferecem, quando muito, um quadro parcial 
do letramento. Hamilton e Barton (1998), por exemplo, questionam a validade de testar se 0 leitor pode compreender uma tabela com horários de ônibus se não soubermos que papel os horários de ônibus desempenham no mundo social do leitor. Em países industrializados, os quais freqüentemente tentam infundir precisão nos seus horários, horários de ônibus são ligados à prática de usar transporte de massa; em países em desenvolvimento onde ônibus passam mais freqüentemente, horários são menos importantes. ${ }^{5}$

Dentre as maiores contribuições que os investigadores dos NLS fizeram estão incluídas: consciência da importância de práticas de apoio na comunidade para a aquisição estável do letramento; reconhecimento da necessidade de considerar a multiplicidade de modos pelos quais as pessoas se comunicam, incluindo o uso de mediadores para decodificar e codificar a palavra escrita; a demonstração de que muitos empregos de baixa qualificação não requerem habilidades de leitura e escrita; e a descoberta de que é possível freqüentar aulas que lidam com habilidades técnicas (por exemplo, no uso e manutenção de veículos, construção civil, carpintaria e solda) sem possuir habilidades de leitura e escrita. Empregando metodologias qualitativas, os NLS mostraram que os indivíduos aprendem a lidar com seu ambiente escrito apesar de sua inabilidade com a palavra escrita. Por exemplo, ao lidarem com documentos oficiais, eles põem um " $x$ " em vez de uma assinatura para receber pagamentos, e buscam auxílio de um parente ou amigo para os ajudarem a decodificar documentos mais extensos. Os NLS também of erecem contribuições sólidas para o planejamento de programas de alfabetização realçando a importância crucial da capacitação de professores para o papel de mediadores e da implementação de trabalhos multissetoriais a fim de oferecer uma base de apoio para o desenvolvimento de hábitos de leitura e escrita. Kell (1996) defende que se treinem agentes de desenvolvimento social como mediadores do letramento - auxiliando a interpretar textos, escrever abaixo-assinados, preencher formulários e treinar as pessoas analfabetas dentro das atividades de desenvolvimento social das quais elas participam.

Diversas pesquisas, independentemente da perspectiva de alfabetização sustentada pelo investigador, mostram que ensinar adultos a se tornarem alfabetizados dentro dos paradigmas escolares resulta freqüentemente em fracasso; eles também mostram que a alfabetização, para ser mantida, deve estar ligada à continuidade da educação. Os NLS fornecem explicações claras de como isso acontece. Entretanto, os NLS apresentam algumas características que podem interferir negativamente na consideração do letramento como um projeto político. Uma dessas características é a não problematização da confiança da pessoa iletrada em outra pessoa, uma condição que poderia criar uma relação muito dependente para o iletrado e que poderia ter ef eitos negativos se 0 "mediador" decidisse levar vantagem sobre o iletrado ou se não houvesse mediadores disponíveis. Uma segunda característica politicamente improdutiva é a afirmação de que uma vez que existem diversos tipos de letramento, o domínio da palavra impressa é apenas uma possibilidade dentre um conjunto maior, sem destaque particular; isto está em desacordo com posições que vêem o domínio da palavra impressa como uma habilidade crucial no lidar com instituições sociais crescentemente complexas. Uma terceira característica é que nos NLS o contexto adquire demasiada importância na

5. Críticas adicionais a comparações internacionais de alfabetização são as de que esses testes são mantidos nas mãos de uns poucos e não são abertos a "controle democrático e validação ética, que se assume que eles são apenas uma questão de medida técnica e que eles não são abertos a especialistas de outras disciplinas e outras bases culturais e ideológicas" (Hautecourt, 2000, p. 364). Em sua defesa, entretanto, os mesmos argumentos podem ser usados contra os testes nacionais aplicados a estudantes do sistema formal de ensino. Os testes de estudantes, porém, não são criticados porque a maioria das pessoas aceita a natureza técnica da sua medida. 
análise; conseqüentemente, 0 indivíduo se torna tão limitado pelo seu ambiente que o letramento funciona quando muito de um modo reativo, raramente pró-ativo.

\section{A lfabetização para o e mpowerment ${ }^{6}$ do indivíduo e da coletividade}

Atualmente existem 872 milhões de adultos analfabetos (um entre quatro) nos países em desenvolvimento. Ao longo dos anos houve uma diminuição na taxa de analfabetismo no mundo, de $33 \%$ em 1990 para $26 \%$ em 2000. A maior parte da diminuição desde 1990 ocorreu na Ásia Oriental, enquanto o número de analfabetos aumentou em 17 milhões no Sul da Ásia e em 3 milhões na África Sub-Saariana. Persistentemente, porém, cerca de dois terços dos analfabetos são mulheres (Unesco, 1999). No Sul da Ásia, onde $44 \%$ da população mais pobre do mundo vive, as mulheres atingem apenas cerca de metade dos anos de escolaridade dos homens, limitando grandemente sua capacidade de produzir renda (Banco Mundial, 2001). Com essa realidade, a tradição de educação popular e 0 engajamento feminista com mulheres adultas têm tomado a alfabetização de modo bastante diferente dos NLS e da perspectiva oficial de alfabetização como meio para maior integração na modernidade e produção. A tradição de educação popular/feminista vê a alfabetização como um elemento essencial para o sujeito desenvolver maior conhecimento e maior entendimento do seu próprio ambiente, e ser, portanto, uma ferramenta necessária, mas não suficiente, para o desenvolvimento de uma cidadania mais efetiva, que não só reconhece os direitos políticos de indivíduos, mas também seus direitos civis e sociais?.

Em uma perspectiva feminista de alfabetização, indivíduos pobres e analfabetos são vistos como capazes de lidar com seu ambiente, sendo evidência disso sua capacidade para sobreviver em condições opressivas. Mas esse modo de lidar com a adversidade não é considerado totalmente aceitável porque os valores de autonomia e autoconfiança podem ser suprimidos em tal processo. Por outro lado, pesquisas sobre as realidades cotidianas de mulheres mostram que as práticas de seu letramento são ligadas a percepção que têm de seus papéis como mães e curadoras da família e, entre mulheres mais velhas, como participantes ativas da igreja (Rockhill, 1987; Gibson, 1996; Stromquist, 1997). Sem dúvida, a opressão e a subordinação moldam o significado e 0 uso do letramento entre mulheres pobres. Mas essa construção do letramento influenciada pelo gênero é vista como problemática e requer modificações.

Enquanto o componente de atribuição de poder, ${ }^{8}$ promovido por perspectivas feministas, busca fazer do letramento uma ferramenta para o incentivo a uma vida política mais ativa nos níveis doméstico, comunitário e nacional, pesquisas sobre mulheres constatam que elas - tanto quanto os homens - participam de projetos de alfabetização por múltiplas razões, algumas educacionais, várias sociais, e muitas psicológicas. Entre as razões educacionais, as necessidades das mulheres são também bastante diversas: para as participantes mais jovens há uma esperança de ingresso no sistema educacional formal e aquisição das credenciais necessárias para mobilidade social; entre aquelas que são casadas, aprender a escrever bilhetes para seus filhos, melhorar sua habilidade para falar e negociar com outros e desenvolver maiores

6. 0 vocábulo empowerment não possui uma palavra que corresponda ao seu significado exato no Português. Como é um conceito que tem sido muito utilizado no meio acadêmico, optamos por mantê-lo, na maioria das vezes, no original. 0 verbo to empower significa conferir poder ou autoridade para agir (N.T.).

7. De acordo com as contribuições feitas por T.H. Marshall (1950), fazemos distinção entre direitos políticos (votar e ter o direito de ser eleito), direitos civis (direito individual a liberdade, igualdade diante da lei, direito à propriedade e direito ao trabalho) e direitos sociais (serviços coletivos, tais como bem-estar social, segurança e educação).

8. Do inglês, empowerment component. (N.T.) 
habilidades de aritmética para controlar compras cotidianas são metas freqüentemente declaradas; entre mulheres mais velhas, assinar 0 nome é um desejo comum (Stromquist, 1997). Também é evidente que muitas mulheres adultas concebem a alfabetização como uma série de tarefas separadas (tais como assinar o nome, ler sinais de rua e ônibus, ler preços em supermercados), em lugar de vê-la como uma habilidade ampla para acessar um discurso e análise mais complexos de seu mundo social, político, e econômico (Stromquist, 1997).

Mulheres enfrentam problemas significativos no domínio do letramento, alguns relacionados simplesmente à sua participação em programas de alfabetização, outros ao desenvolvimento de práticas de letramento duradouras. Quando as mulheres ingressam em turmas de alfabetização, elas se deparam com o desafio de participar regularmente das aulas, uma vez que estas competem na divisão do tempo entre muitas outras demandas simultâneas da vida cotidiana, especialmente para mulheres pobres. Seu papel como mães e como aquelas que cuidam da família significam que virtualmente todo problema familiar que emerge adquire maior prioridade que assistir às aulas. Rockhill (1987) adverte que, para uma análise de gênero do letramento, é importante não ver o lar como uma coletividade unificada, mas sim como um cenário no qual as mulheres experimentam demandas e interesses divergentes e contraditórios. A descontinuidade criada por alguns eventos domésticos impede que as muIheres apresentem progresso regular e termina por desencorajar sua participação. Além disso, rotinas de trabalho doméstico como cozinhar, lavar, limpar a casa, e levar e buscar as crianças na escola, freqüentemente não requerem habilidades de leitura e escrita. Entre as mulheres pobres que trabalham fora da casa, trabalhos como o de empregadas domésticas e cozinheiras são também atividades que não requerem habilidades de leitura e escrita, exceto em casos raros (Stromquist, 1997).
Outra característica que afeta mulheres estudantes de alfabetização é a de que muitas delas vêm para as aulas trazendo experiências traumáticas de casa, como sofrimentos físico e psicológico significativos. 0 trabalho de Horsman no Canadá com mulheres migrantes (1997) mostra que problemas domésticos caracterizados por agressões e insultos, migrações provocadas por estupro e a vida com parceiros que bebem excessivamente afetam negativamente a freqüência e concentração em sala de aula e criam necessidades de apoio emocional entre as mulheres adultas, que os professores de alfabetização raramente estão preparados para atender.

Talvez o principal desafio no uso do letramento como uma ferramenta para empowerment resida nas mensagens recebidas pelas mulheres ao participar de aulas de alfabetização. Freqüentemente, o conteúdo de programas de alfabetização transmite mensagens cuja linguagem expressa ideologias de gênero profundamente enraizadas, que atribuem às mulheres papéis eminentemente reprodutivos e sustentam concepções convencionais de feminilidade e masculinidade (Stromquist, 1997; Patel, 1987). Para promover a cidadania das mulheres, então, é essencial oferecer contradiscursos nos quais a possibilidade do engajamento ativo de mulheres em transformação social nos níveis micro e médio seja colocada. Isso implica planejar as aulas de alfabetização de modo a encorajar o engajamento do estudante por meio de pedagogias alternativas e não autoritárias tais como conversas, jogos, dramatizações e teatro popular. Também implica que professores de alfabetização tenham consciência das questões envolvendo gênero e que sejam treinados para administrar aulas de alfabetização que utilizem as experiências e habilidades dos adultos em lugar de reproduzir formas escolares de educação, freqüentemente semelhantes às de uma sala de aula de primeiro ano. 
Aqueles que vêem o letramento como uma ferramenta para empowerment de mulheres baseiam-se em pesquisas, em educação, para fundamentarem suas demandas por letramento. A alfabetização é vista como o primeiro passo em direção à educação em geral. Assim, embora pesquisas em alfabetização indiquem que a alfabetização por si só pode não produzir a formação de conceitos, pode ser solidamente argumentado que os hábitos de leitura que advêm da educação adicional capacitam os indivíduos a obter acesso a informações mais sofisticadas, complexas e detalhadas - o que, por sua vez, pode ajudar as pessoas a adotar posições e preferências melhor informadas e mais defensáveis.

Pesquisas sobre o letramento de mulheres mostram que seus papéis domésticos também criam espaços potencialmente úteis para sua atuação. Dado que as mulheres assumem responsabilidade pelas crianças e pela administração das famílias, são elas que devem ver e responder às comunicações da escola e órgãos do governo (a respeito de tópicos tais como pagamento de contas, serviços sociais e impostos). Embora não seja reconhecido por muitos dentro do lar, de fato a mulher executa uma série de práticas de letramento que Ihe conferem poder na família, por meio de sua interação com outras pessoas para tratar de assuntos em nome dos seus (Gibson, 1996; Rockhill, 1987). Em contraste com o que ocorre em casa, por causa da natureza dos empregos que mulheres e homens pobres possuem, o local de trabalho capacita mais os homens do que as mulheres a praticar atividades envolvendo o letramento e, portanto, a experiência do emprego é mais instrumental ao empowerment dos homens (Gibson, 1996).

A concepção do letramento como empowerment é atualmente mais um desejo do que uma realidade. Apesar disso, seu potencial pode ser vislumbrado. Giroux, um educador que utiliza a teoria crítica em seu trabalho, define educação política (e, portanto, empowering) da seguinte forma:
Educação política significa descentralizar 0 poder na sala de aula e em outras unidades pedagógicas, de modo que a dinâmica daquelas desigualdades institucionais e culturais que marginalizam alguns grupos sociais, reprimem certos tipos de conhecimento e suprimem o diálogo crítico, possa ser abordada. (1999, p. 255)

Dando continuidade a essa perspectiva, McLaren, outro estudioso da teoria crítica, explica que a pedagogia transformadora não significa confinar a realidade, mas sim em buscar reestruturá-la por meio do questionamento de crenças tradicionais e do desafio de práticas sociais. É preciso também, ao mesmo tempo, estar consciente da relação de poder/conhecimento existente entre o professor e o aluno. Ele afirma:

A referência básica para 0 empowerment dos grupos desejosos não deveria ser sua estranheza ou deslocamento para além das fronteiras do dominante e familiar em questões morais, étnicas, de gênero ou políticas, mas sim o estabelecimento de critérios que possam distinguir alegações de superioridade moral, étnica, de gênero ou políticas que nós fazemos como indivíduos externos a esses grupos. (M cLaren, 1992, p. 333)

As contribuições das três perspectivas de letramento que revimos acima revelam que 0 termo "analfabeto" admite variabilidade substancial em termos de habilidades de leitura e escrita. Há também considerável variabilidade nos objetivos que os estudantes almejam alcançar por meio da sua participação em programas de alfabetização. Os estudos produzidos sob cada perspectiva, embora reconhecendo a importância da alfabetização individual, diferem quanto ao papel atribuído a ela. Alfabetização como habilidade básica e alfabetização como empowerment buscam habilidade de alfabetização no nível individual; em contraste, as perspecti- 
vas dos NLS dispõem-se a aceitar a mediação de outras pessoas no acesso à comunicação escrita. Da perspectiva dos NLS o que interessa, parece, é que determinada função é exercida não importando quem a executa. A questão da autonomia individual (ou dependência), deve ser observado, não pode ser determinada empiricamente. Valores têm um papel substancial na decisão sobre sua relevância.

Embora as três perspectivas concordem que práticas de letramento tornam-se estáveis dependendo do grau em que a comunidade na qual 0 indivíduo vive abriga instituições e atividades que requerem letramento, a perspectiva do empowerment seria mais pró-ativa em termos de tentar modificar o ambiente de modo que o letramento possa emergir; o contexto seria considerado crucial, mas não um determinante completo da possibilidade de emergir o letramento como uma prática social. Diferentemente dos NLS, a perspectiva do empowerment estaria mais propensa a ver o contexto como uma construção social sujeita à influência coletiva e à intervenção do Estado.

A perspectiva que vê o letramento como profundamente enraizado em práticas contextuais veria o conteúdo como algo a ser documentado, não moldado. A perspectiva que entende a alfabetização como uma habilidade básica para o desenvolvimento vê o conteúdo como importante. No entanto, o conteúdo que ela advoga move os indivíduos no sentido de sua integração ao status quo, principalmente ao torná-los indivíduos mais "modernos" (mais eficientes, mais qualificados, melhores pais). A perspectiva do empowerment atribuiria grande importância ao conteúdo e o veria como um dos principais meios por meio dos quais o letramento torna-se promissor para os grupos menos favorecidos. 0 letramento atingiria seus objetivos emancipatórios apenas se o conteúdo dos programas de alfabetização - isto é, a natureza das mensagens obtidas e processadas nas aulas de alfabetização e a capacidade de exercer o pensamento crítico acerca das mensagens sociais dominantes - for progressista e promova sua consciência social, particularmente consciência de gênero e empowerment por parte das mulheres. E, uma vez que objetivos emancipatórios não podem ser atingidos por meio dos modos prescritivos usuais de ensino, as aulas de alfabetização teriam que se engajar em modos mais participativos e dialógicos de ensino e aprendizado para que tais objetivos fossem atingidos.

0 enraizamento social do letramento constitui-se tanto num paradoxo quanto em um grande desafio. 0 paradoxo é: 0 letramento é necessário para adquirir conhecimento e transcender o local; no entanto, se o local não dá suporte, o letramento não lança raízes. 0 desafio é: oferecer programas de alfabetização para adultos ao mesmo tempo em que se criam ambientes que alimentem o letramento. Isto requer ação no nível educacional, mas também a participação de instituiç̧ões governamentais e não-governamentais no oferecimento de medidas compatíveis com, ou que dêem apoio a, o letramento em outros setores sociais.

As três perspectivas coincidem em reconhecer que a adoção bem-sucedida de habilidades de alfabetização entre adultos está longe de ser fácil. Ela requer uma boa compreensão das características e necessidades dos estudantes adultos; métodos educacionais que os reconheçam e os tratem como indivíduos com experiências ricas e diversas; capacitação de professores para lidar com questões tanto cognitivas quanto emocionais; e investimentos paralelos em outros setores econômicos e sociais. Para ser bem-sucedido, o letramento deveria ser um projeto de longo prazo, sólido e de uma agência com acesso a recursos - em outras palavras, o Estado teria que assumir um papel preponderante.

\section{Justapondo alfabetização e pobreza}

Antes de considerarmos que programas de alfabetização podem ser solucionados 
como uma iniciativa meramente educacional, lembremo-nos de que o analfabetismo não é distribuído aleatoriamente. Ele afeta sobretudo pessoas pobres. Ao examinarmos o problema da pobreza entre a maioria dos "analfabetos", fica claro que suas necessidades de sobrevivência surgem com urgência muito maior e vêm muito antes de qualquer necessidade educacional. Em muitas regiões em desenvolvimento a pobreza se deu por causa da má distribuição de recursos ao longo de muitos anos de conquista e de dominação coIonial. Há, portanto, um campesinato desprovido de poder que continua a ter acesso limitado aos benefícios nacionais. Para os pobres do campo, as principais estratégias de sobrevivência são o trabalho assalariado, a migração por trabalho e os projetos de geração de renda (Grindle, 1986). Não é de surpreender que estudos de casos recentes, conduzidos pelo Banco Mundial (1999a), com 147 pessoas que se livraram da pobreza, mostraram que 0 auto-emprego ou empreendedorismo são suas saídas mais freqüentes. A estas se seguem a renda de salários, benefícios da família, renda da agricultura e acesso a terra. Qualificações obtidas para conduzir um negócio ou qualificações específicas foram mencionadas como importantes em apenas $27 \%$ dos casos. Por outro lado, apenas $15 \%$ dos indivíduos entrevistados mencionaram a educação como uma estratégia eficaz, com variação considerável entre regiões geográficas; enquanto de 20 a $30 \%$ em países da América Latina e antiga União Soviética viam o valor da educação, cerca de 4 a 7 \% o faziam na África e Ásia (Banco Mundial, 1999a, p. 47).

0 empowerment de mulheres não pode existir independentemente da resolução de complexos problemas socioeconômicos. A maioria dos programas que enfocam a condição das mulheres pobres não inclui soluções de problemas envolvendo a redistribuição de bens. Taylor (1997) observa que na África do Sul a reforma agrária e a restituição de terras não são consideradas paralelamente a programas de sustento permanente, garantia de alimento e microcrédito para o benefício de mulheres pobres; também ausente é o treinamento das mulheres para desempenhar papéis em indústrias do setor secundário, tais como processamento de alimentos, construção de máquinas agrícolas e produção de fertilizantes. Observações semelhantes podem ser feitas sobre planos nacionais que enfocam as mulheres em outros países em desenvolvimento. E o fato de que a maioria das mulheres indigentes é casada com homens indigentes cria problemas adicionais para a elevação da condição social das mulheres. Sob condições de pobre$z a$, os homens também experimentam sentimentos de impotência e baixa auto-estima. Se eles não conseguem empregos, mas as mulheres conseguem, os papéis e identidades dos homens se tornam confusos e contraditórios (Silberschmidt, 2001).

Uma conseqüência das estratégias neoliberais é aquilo que se conhece por "Nova Agenda de Políticas". Como conseqüência dessa abordagem, o papel do Estado tem sido circunscrito apenas à oferta de um ambiente de apoio a esquemas privados e a reduzir gastos públicos com serviços sociais (Rutherford, 1999). Um importante elemento das estratégias neoliberais para reduzir o tamanho do Estado, refletido na ampla adoção de Programas de Ajuste Estrutural (PAEs ${ }^{9}$ ) por países em desenvolvimento com dívidas externas, tem enfraquecido a capacidade do Estado para produzir políticas so ciais e sua capacidade administrativa para executá-las. 0 Banco Mundial, juntamente com o Fundo Monetário Internacional, é um agente-chave na aplicação de PAEs. Sob críticas por aumentar a pobreza em todo o Terceiro Mundo, o Banco Mundial veio com medidas para "aliviar a pobreza". Um documento exemplar a esse respeito é o relatório de 2000/2001 sobre

9. Em inglês, SAP (Structural Adjustment Programs) (N.T.). 
Desenvolvimento Mundial denominado A tacando a Pobreza ${ }^{10}$ (Banco Mundial, 2000). 0 relatório propõe uma estratégia tríplice, em que não se reconhecem o impacto negativo dos PAEs ou fatores estruturais tais como as bases desiguais de comércio ou a concentração de terras (e o número simultaneamente grande de famílias sem terra) em países em desenvolvimento. ${ }^{11}$ Especificamente no caso de mulheres pobres, o documento do Banco Mundial propõe seu empowerment, mas ignora os grupos organizados de mulheres já existentes como fontes potenciais de empowerment. Mulheres, portanto, aparecem quando muito como "populações-alvo" e não como grupos cruciais a serem mobilizados.

Ao lermos sobre o tipo de empowerment que o Banco M undial vislumbra para as mulheres, fica claro que ele deverá ser obtido por meio de meios políticos formais. Entretanto, sabemos mediante a literatura sociológica, antropológica e feminista que o empowerment das mulheres não deve significar simplesmente aumentar sua representação em assembléias nacionais e sociais e oferecer exemplos simbólicos de suporte a agricultura e microempresas. As mulheres precisam que muito mais fundos sejam alocados no nível individual para crédito e auxílio técnico em escala nacional. Elas precisam também de muito mais apoio financeiro no nível coletivo, de modo que elas possam fortalecer organizações de base e não-governamentais com níveis mais elevados de capacidade institucional. Como podemos levar a sério a declaração de que as pessoas pobres precisam receber apoio para o desenvolvimento de seu capital social se nenhuma medida específica pode ser identificada para o financiamento de organizações de base e ONGs?

Fundos de Investimento Social (daqui em diante denominados $F\left(S s^{12}\right.$ ), introduzidos pelo Banco Mundial e apoiados por outros bancos regionais e pela maioria das agência bilaterais de desenvolvimento, deveriam ser um mecanismo para atender as necessidades dos segmen- tos mais pobres da população, que foram negativamente afetados pelos modelos econômicos neoliberais. Esses FISs são relativamente pequenos e oferecem emprego temporário para a construção de escolas, postos de saúde, estradas e canais d'água. Porém, tem-se observado que, pelo menos no caso do Peru, esses fundos não cobrem as despesas de manutenção de tais infra- estruturas. Eles tendem a gerar clientelismo e aumentar a dívida externa do país, uma vez que são parte de empréstimos renegociados (Ballon, 1999). Eles não ajudam as mulheres, porque elas não constituem a maioria dos empregados. Mais criticamente, uma vez que o apoio não é dado como um direito social, mas sim focalizando os mais pobres dentre os pobres, os FISs freqüentemente funcionam como caridade, formas de assistência que dependem da boa vontade de líderes políticos ou de organizações internacionais (Vargas, 1999). Tal apoio não contribui para diminuir a desigualdade social e é duvidoso que ele ofereça a retaguarda que as pessoas pobres precisam para se envolverem em programas de alfabetização.

Retóric a e prática divergentes

A perspectiva da alfabetização como habilidade básica, valer dizer, a perspectiva oficial dominante, tende a ser muito retórica. Ela argumenta a favor da importância da alfabetização, mas mostra pouco interesse em informar-se sobre sua complexidade e menos ainda em comprometer os recursos necessários para enfrentá-la. Um desencontro peculiar ocorre entre a importância oficialmente

10. Título original, Attacking Poverty (N.T.).

11. A maior parte das recomendações contidas em Attacking Poverty não reflete sólida fundamentação teórica ou resultados de pesquisas empíricas. Como exemplo ilustrativo, a demanda por descentralização não contempla o fato de que algumas comunidades provavelmente não sejam a favor dos pobres (Oyen, 2001) ou a favor da justiça social para mulheres.

12. Em inglês, SIF (Social Investment Fund) (N.T.). 
proclamada da alfabetização e os recursos dedicados a atingi-la. Mesmo nos Estados Unidos, onde investimentos estaduais e federais na educação de adultos cresceram substancialmente na década passada, tais investimentos são "ainda triviais em relação ao investimento na escolarização formal e às crescentes necessidades em educação de adultos" (Wagner and Venezky, 1999, p. 26). Na maior parte dos países em desenvolvimento, o apoio à educação de adultos, da qual a alfabetização é a maior parte, representa menos de $3 \%$ do orçamento nacional para educação. 0 padrão dominante mostra uma série de projetos pequenos e sem bases, mal financiados e sem nenhuma tentativa de oferecer uma alfabetização sensível ao substancial conjunto de resultados de pesquisas já disponível.

0 encontro "Educação para Todos" (EFA) ocorrido em 1990, em J omtien, Tailândia, registrou um claro reconhecimento da importância da alfabetização, especialmente entre as mulheres e expressou a meta de reduzir "maciçamente" a taxa de analfabetismo até 0 ano 2000 (UNDP et al., 1990). De acordo com estatísticas da Unesco, a taxa de analfabetismo mundial era de $33 \%$ em 1990 e de $26 \%$ em 2000. Isso significa que a redução foi de cerca de $20 \%$, que dificilmente pode ser considerada "maciça". No encontro de Dacar em 2000, para se avaliar o cumprimento dos objetivos do encontro "Educação para Todos", foi decidido que a nova meta de alfabetização seria a de reduzir 0 analfabetismo em 50\%, mas desta vez até 2015 (World Education Forum, 2000). 0 adiamento do prazo não foi acompanhado de nenhum resultado de pesquisa ou reflexão sobre a implementação de esforços nacionais passados. Essa nova meta de alfabetização deve ser tomada com um dos exemplos mais flagrantes do jogo de retórica e da ausência de qualquer intenção séria de corrigir desempenhos passados.

Além de Dacar, pode ser visto que a alfabetização não comparece em nenhum grande plano nacional para reforma educacional. Pou- quíssimos recursos públicos continuam sendo alocados a programas de alfabetização. De fato, observa-se que o apoio à educação de adultos é hoje uma pequena fração do que foi no final da década de 1970 . Klees (a ser publicado), analisando o conteúdo da mais recente versão da Política de Educação do Banco Mundial (World Bank, 1999b), constata que o Banco Mundial evita a expressão "educação de adultos", preferindo falar de "educação continuada". ${ }^{13}$ Ainda assim, a educação continuada, embora mencionada no texto do documento sobre as políticas, não aparece em suas "diretrizes recomendadas para políticas" (discutidas nas páginas 31-36 do documento sobre as políticas do Banco Mundial).

A educação, talvez mais do que qualquer outra alínea social, reflete a noção de uma sociedade justa, que oferece oportunidades iguais para todos. Outros serviços públicos asseguram o acesso a um nível mínimo de benefícios (saúde, educação compulsória, seguridade social, bem-estar social básico) e têm um caráter compensatório, sendo, assim, também distributivos; é, porém, a educação que busca um caráter igualitário e, por vezes, chega a adotar formas de discriminação positiva, tais como ação afirmativa e concessão de bolsas de estudo (Enguita, 1996).

A alfabetização pode ser particularmente útil para os idealizadores de políticas públicas porque não é uma política redistributiva. Ela se propõe a distribuir o conhecimento sem tirar bens de ninguém para fazê-lo. Uma vantagem das políticas redistributivas é que seu impacto na igualdade é mais imediato do que o de outras políticas. Elas têm, entretanto, três desvantagens: elas são difíceis de implementar, a transferência de riqueza supostamente tem 0 efeito de diminuir o incentivo à geração de riqueza e, o mais importante, políticas de redistribuição - que afetam os

13. Em inglês, lifelong learning (N.T.). 
bens e renda de outras pessoas - tendem a ser altamente conflituosas (Saavedra-Rivano, 2001). De fato, a redistribuição de bens jamais ocorreu em circunstâncias normais e teme-se que seus benefícios sejam sobrepujados pela ruptura social que tal política causa.

Concluindo, deve ser dito que o mundo do letramento é complexo e caracterizado pela contradição e negligência. Pesquisas têm feito progresso na definição do letramento, no entendimento das variações nas quais ele existe e em reconhecer a importância de suporte contextual para possibilitar o desenvolvimento de hábitos duradouros de leitura e escrita. Posições feministas defendem o letramento como um pré-requisito para a conquista de uma cidadania mais ampla.

A maior parte dos governos e organizações humanitárias aprova visivelmente o letramento, mas quase todos tendem a superestimar seus efeitos e a subestimar as dificuldades da sua implementação. Nem governos nem organizações humanitárias têm demonstrado 0 tipo de comprometimento necessário para tornar o letramento acessível aos adultos a que eles pretendem servir. A conclusão mais clara que se pode tirar da observação dos investimentos nacionais e internacionais em letramento é a de que adultos carregam um grande valor simbólico e, assim, suas necessidades - incluindo aquelas associadas à condição desprivilegiada das mulheres - são publicamente reconhecidas. Infelizmente, 0 reconhecimento simbólico não tem sido acompanhado pelo reconhecimento e utilização dos resultados de pesquisas sobre letramento e menos ainda por investimentos sociais e educacionais compatíveis com a conquista e estabelecimento de práticas e habilidades de letramento.

\section{Referências bibliográficas}

BALLON, Eduardo. Fondos de inversión social y gasto social en América Latina: una aproximación preliminar. In; Narda HENRIQUEZ (ed.), Construyendo una Agenda Social. Lima: Fondo Editorial, 1999. p. 233-251.

BARTON, David. Literacy: An Introduction to the Ecology of Written Language. Oxford: Blackwell, 1994. . and Mary HAMILTON. Local Literacies: Reading and Writing in One Community. London: Routledge, 1998.

BARTON, Paul. Policy What J obs Require: Literacy, Education, and Training, 1940-2006. Princeton: Information Center, Educational Testing Service, 1999.

BERNARD0, Allan. Literacy and the Mind. The Contexts and Cognitive Consequences of Literacy Practice. Hamburg: Unesco Institute of Education, 1998.

BREIER, Mignonne, Matsepela TAETSANE, and Lynette SAIT. Reading and writing in the minibus taxi industry. SOUL Research Report n. 6. Cape Town: Department of Adult Education and Extra-Mural Studies, University of Cape Town, 1996.

DEXTER, Emily R., Sarah E. LEVINE, and Patricia VELASCO. Maternal Schooling and Health-Related Language and Literacy Skills in Rural Mexico. Comparative Education Review, vol. 42, n. 2, p. 139-162. 1998.

DRUINE, Nathalie and Danny WILDEMEERSCH. The Vocational Turn in Adult Literacy Education and the Impact of the International Adult Literacy Survey, International Review of Education, vol. 46, no. 5, 2000, p. 391-405.

ENGUITA, Mariano. Os desiguais resultados das politicas igualitárias. Classe, gênero e etnia na educação. Revista Brasileira de Educação, no. 3, p. 5-17, setembro-dezembro 1996.

FERREIRO, Emilia. Children's Literacy and Public Schools in Latin America. In D,A, WAGNER and L.D. PUCHNER (eds.), World Literacy in the Year 2000, vol. 529 of The Annals of the American Academy of Political and Social Sciences. Newbury Park: Sage, 1992. 
GEE, J ames. Social Linguistics and Literacies: Ideology in Discourses. London: Taylor and Francis, 1996.

GEE, J ames, Glynda HULL, and Colin LANKSHEAR. The New Work Order. Sydney: Allen and Unwin, 1996.

GIBSON, J ohn. Literacy and Intrahousehold Externalities. World Development, vol. 29, no. 2, 2001, p. 155-166.

GIROUX, Henry. Doing Cultural Studies: Youth and the Challenge of Pedagogy. In: Michael PETERS (ed.). After the Disciplines. The Emergence of Cultural Studies. Westport: Bergin and Garvey, 1999, p. 229-265.

GRINDLE, Merilee. State and Countryside Development Policy and Agrarian Politics in Latin America. Baltimore: The J ohns Hopkins University Press, 1986.

HAMILTON, Mary and David BURTON. The International Adult Literacy Survey: What Does It Really Measure? International Review of Education, vol. 46, no. 5, 2000, p. 377-389.

HAUTECOEUR, J ean-Paul. Editorial Introduction; Literacy in the Age of Information: Knowledge, Power or Domination? International Review of Education, vol. 46, no. 5, 2000, p. 357-365.

HEATH, Shirley. Literacy and Social Practice. In Daniel A. WAGNER, Richard L. VENEZKY, and Brian V. STREET (eds.). Literacy. An International Handbook. Boulder: Westview Press, 1999, p. 102-106.

HEATH, Shirley. Ways with Words. New York: Cambridge University Press, 1983.

HORSMAN, J enny. "But I'm Not a Therapist." Further Discussion with Literacy Work with Survivors of Trauma. Toronto: Spiral Community Resource Group, 1997, draft.

KELL, Catherine. Submission to Language Task Group on Literacy. Cape Town: Department of Adult Education and Extra-Mural Studies, University of Cape Town, April 1996, draft.

KELL, Catherine and Mastin PRINSLO0. Towards a Critique of Adult Basic Education and Training Policy: Research of the Social Uses of Literacy in South Africa. Cape Town: University of Cape Town, c. 1997, draft.

KLEES, Steven. World Bank Education Policy: New Rhetoric, Old Ideology. International Journal of Educational Development, forthcoming.

LANKSHEAR, Colin and Peter O'CONNOR. Response to "Adult Literacy: The Next Generation," Educational Researcher, vol. 28, no. 1, 1999, p. 30-36.

MARSHALL, T.H. Citizenship and Social Class and Other Essays. Cambridge: Cambridge University Press, 1950.

MCEWAN, Mary-J ane and LiezI MALAN. "The kind of education I have, one cannot see." Perceptions and uses of literacy in rural Eastern Cape. SOUL Research Report No. 11. Cape Town: Department of Adult Education and Extra-Mural Studies, University of Cape Town, 1996.

MCLAREN, Peter. Literacy Research and the Postmodern Turn: Cautions from the Margins. In: Richard BEACH, J udith GREEN, Michael KAMIL, and Timothy SHANAHAN (eds.). Multidisciplinary Perspectives on Literacy Research. Urbana; National Council of Teachers of English, 1992, p. 319-339.

MURRAY, T. Scott. International Adult Literacy Household Survey M ethods. In: Daniel A. WAGNER, Richard L. VENEZKY, and Brian V. STREET (eds.). Literacy. An International Handbook. Boulder: Westview Press, 1999, p. 217-223.

OYEN, Else. Six Questions to the World Bank on the Word Development Report 2000-2001: Attacking Poverty. Critique organized by the International Social Science Council through its Comparative Research Program on Poverty. 2001. Available at http://www.crop.org/wdrcom.htm.

PATEL, Ila. Policy and Practice on Adult Education for Women in India 1970-84. Stanford: Stanford University, Ph.D. dissertation, 1987.

ROGERS, Alan. Some Contemporary Trends in Adult Literacy from an Intermational Perspective. Adult Education and Development, 56, 2001, p. 21-31. 
RUTHERFORD, Blair. Civil (Dis)Obedience and Social Development in the New Policy Agenda: Research Priorities for Analyzing the Role of Civil Society Organizations in Social Policy Reform, with particular attention to Sub-Saharan Africa and Latin America. Ottawa: IDRC, February 1999.

SAAVEDRA-RIVANO, Neantro. Equity, Development, and Public Policies. In J ames MCGUIRE (ed.), Rethinking Development in East Asia and Latin America. Proceedings a workshop sponsored by the Pacific Council on International Policy and the Center for International Studies, USC, April 1997.

SCRIBNER, Sylvia and Michael COLE. The Psychology of Literacy. Cambridge, Massachusetts: Harvard University Press, 1981.

SILBERSCHMIDT, Marghrette. Disempowerment of Men in Rural and Urban East Africa: Implications for Male Identity and Sexual Behavior. World Development, no. 29, no. 4, 2001, p. 657-671.

STREET, Brian (ed.). Cross-Cultural Approaches to Literacy. New York: Cambridge University Press, 1993.

STREET, Brian. Literacy in Theory and Practice. Cambridge: Cambridge University Press, 1984.

STREET, Brian. Social Literacies: Critical Approaches to Literacy in Development, Ethnography and Education. Longman: London, 1995.

STROMQUIST, Nelly P. Literacy for Citizenship. Gender and Grassroots Dynamics in Brazil. Albany: State University of New York Press, 1997.

TAYLOR, Viviene. Economic Gender Injustice: The Macro Picture. Agenda, no. 33, 1997, p. 9-25.

TEASDALE, G.R. Globalization, Localisation: Impacts and Implications for Teacher Education in the Asia-Pacific Region. Paper presented at the annual conference of the Australian Teacher Education Association, Queensland, 5-8 J uly 1987.

UNDP, UNESCO, UNICEF, and World Bank. Final Report. World Conference on Education for All: Meeting Basic Needs. New York: UNDP, 1990.

VARGAS, Virginia. La ciudadanía: un debate feminista en curso. In: Narda Henriquez (ed.), Construyendo una Agenda Social. Lima: Fondo Editorial, 1999. p. 313-336.

WAGNER, Daniel A. and Richard L. VENEZKY. Adult Literacy: The Next Generation. Educational Researcher, vol. 28, no. 1, p. 21-29, 1999.

WINDHAM, Douglas M. Literacy and Economic Development. In Daniel A. WAGNER, Richard L. VENEZKY, and Brian V. STREET (eds.). Literacy. An International Handbook. Boulder: Westview Press, 1999, p. 342-347.

WORLD BANK. World Development Report 2000/2001. Attacking Poverty. Washington, D.C.: The World Bank, 2000. WORLD BANK. Poverty Trends and Voices of the Poor. Washington, D.C.: The World Bank, 2 December, 1999a.

WORLD BANK. World Bank Education Strategy. Washington, D.C.: The World Bank, 1999b.

WORLD EDUCATION FORUM. Final Report. Dakar: World Education Forum, 26-28 April 2000.

Recebido em 16.10.01

Aprovado em 12.12.01

Nelly P. Stromquist é professora no Rossier School of Education na University of Southern California. Estuda Educação de Adultos nos países do Terceiro Mundo, em especial América Latina e as relações de gênero. Em 1997 publicou estudo sobre as mulheres no MOVA-SP. 